\title{
FUSION OF AXIS WITH THIRD CERVICAL VERTEBRA
}

\author{
Priya Pramod Roy1, Doshi Megha Arun², Swapna Ajay Shedge 3
}

${ }_{1}^{1}$ Associate Professor, Department of Anatomy, KIMS, Karad, Maharashtra, India.

2 Professor and HOD, Department of Anatomy, KIMS, Karad, Maharashtra, India.

${ }^{3}$ Assistant Professor, Department of Anatomy, KIMS, Karad, Maharashtra, India.

ABSTRACT
BACKGROUND
nuring the embryological development if there is any fusion of the contiguous vertebra, it will result in the distraction or failure of
normal development. The fusion of the vertebra may be congenital or acquired. However, the acquired is rare. Major problem with
block vertebra is that they restrict the movements and results in several neurological disorders.

\section{MATERIALS AND METHODS}

This study is carried out in Department of Anatomy, Krishna Institute of Medical Sciences, Karad. We have observed 28 vertebrae and the axis was found to be fused with 3rd cervical vertebra. This fused vertebra was assessed and the photograph of the specimen was taken.

\section{RESULTS}

Among a total of 28 vertebrae examined, we identified 3 specimens of block vertebra which accounted for a total incidence of $0.10 \%$. Figure 1 and 2 shows photographs of all 28 vertebrae and block vertebra taken from anterior and posterior aspects. The fusion included facet fusion, vertebral arch fusion and vertebral body fusion.

\section{CONCLUSION}

The observed incidence of fused cervical vertebrae in the present study was $0.10 \%$. As the fusion of cervical vertebrae is associated with several clinical manifestations, early diagnosis is recommended. Further, more studies have to be undertaken in this area to understand and to diagnose early and also to develop more effective management techniques for the benefit of the society in general.

\section{KEY WORDS}

Vertebra, Fusion, Block Vertebra, Clinical Anatomy.

HOW TO CITE THIS ARTICLE: Roy PP, Arun DM, Shedge SA. Fusion of axis with third cervical vertebra. J. Evolution Med. Dent. Sci. 2018;7(34):3763-3765, DOI: 10.14260/jemds/2018/845

\section{BACKGROUND}

There are total seven cervical vertebrae, out of which cervical vertebra three to six are considered as typical and cervical vertebra 1, 2, 7 are considered as atypical as they have different characteristic features. ${ }^{1}$ The process of development is more complex for second cervical vertebra. ${ }^{2}$ During the embryological development if there is any fusion of the contiguous vertebra, it will result in the distraction or failure of normal development. ${ }^{3}$ It was reported that there will be change in the craniofacial morphology if there is any failure of normal development of vertebra due to the fusion. ${ }^{4}$ In fact there may be severe pain in the neck and even leads to sudden death. 5 The fusion of the vertebra may be congenital or acquired. However, the acquired is rare. ${ }^{6}$ Major problem with block vertebra is that they restrict the movements and results in several neurological disorders. However, the severity depends on the extent and number of vertebra involved. Hence, understanding the abnormalities in vertebra

'Financial or Other Competing Interest': None.

Submission 13-07-2018, Peer Review 06-08-2018,

Acceptance 12-08-2018, Published 20-08-2018.

Corresponding Author:

Priya Pramod Roy,

Department of Anatomy,

Krishna Institute of Medical Sciences,

Karad, Maharashtra, India.

E-mail: priyaproy7@gmail.com

DOI: $10.14260 /$ jemds $/ 2018 / 845$ is not only an academic interest, but also important at clinical point of view as this is a topic of interest in clinical subjects like orthopaedics, neurology and neurosurgery. Blocked vertebrae may result in increase in the biomechanical stress in the adjoining segments and cause to degenerative changes. Further, it causes the rupture of ligaments and also tear of intervertebral disc. The current study was undertaken to observe the incidence of fusion of axis with third cervical vertebra.

\section{MATERIALS AND METHODS Study Setting}

The present descriptive study was carried out in Department of Anatomy, Krishna Institute of Medical Sciences, Karad.

\section{Methods}

We have observed 28 vertebrae and the axis was found to be fused with 3rd cervical vertebra. This fused vertebra was assessed, and the photograph of the specimen was taken.

\section{RESULTS}

Among a total of 28 vertebrae examined, we identified 3 specimens of block vertebrae which accounted for a total incidence of $0.10 \%$. Figure 1 and 2 shows photographs of all 28 vertebrae and block vertebrae taken from anteriorposterior aspects. The fusion included facet fusion, vertebral arch fusion and vertebral body fusion. 


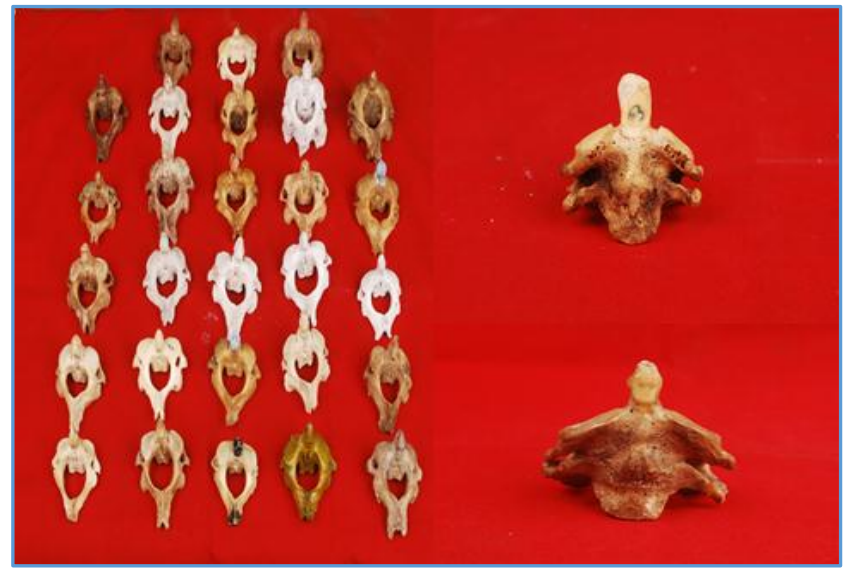

Figure 1. Photographs of all 28 Vertebrae and Block Vertebra taken from Anterior and Posterior Aspects

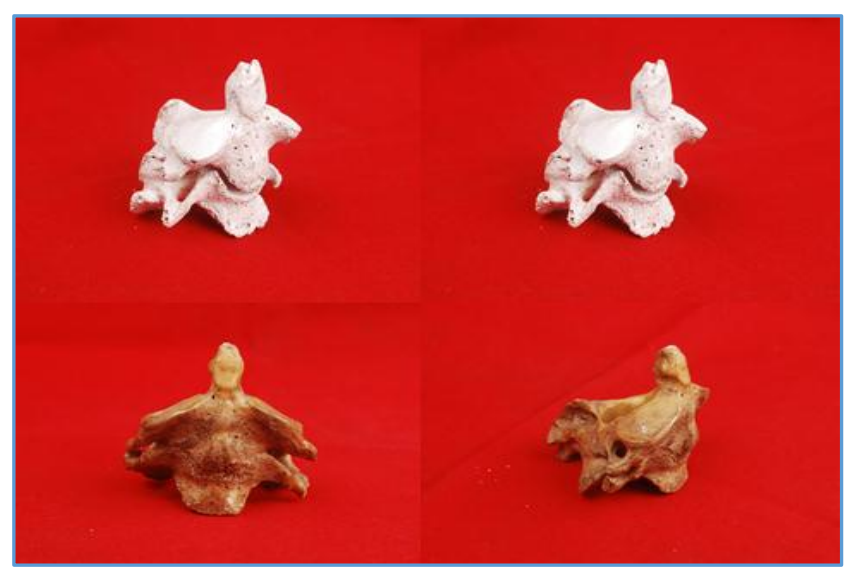

Figure 2. Photographs of Block Vertebra taken from Anterior and Posterior Aspects

\section{DISCUSSION}

Abnormalities during the time of development leads to fusion of the vertebra. Further, decrease or total absence of blood supply during the development also contributes for abnormal segmentation. ${ }^{7}$ As the fusion may be congenital or acquired, it is mandatory to differentiate the cause. This can be identified through observing the presence of trauma if any and also observing the x-ray evidences. ${ }^{8}$ The intervertebral disc is absent in case of fusion due to congenital cause. ${ }^{9}$ It was reported that the incidence of fusion of the vertebra was fusion of second and third cervical vertebra when compared to other vertebral fusions. ${ }^{10}$ This type of vertebral fusions result in abnormalities in the posture and also cause prolapse of disc. ${ }^{11}$ Hence, the fusion of the vertebra has both embryological and clinical significance. The present study was undertaken to observe the incidence of fusion of axis with third cervical vertebra. The incidence observed was 0.10 percentages. Earlier studies reported that the incidence of fused second cervical vertebra with third was $0.5 \% .{ }^{12}$ Another study conducted by Sharma $\mathrm{M}$ et al, $6.25 \%$ of cervical vertebrae fusion in 48 dried adult vertebral columns. ${ }^{13}$ Soni et al reported that the observed incidence of fusion was $0.4-0.7$ percentage. ${ }^{11}$ Our study results are in accordance with earlier studies.

The fusion must be diagnosed in the early stages because the result of the fusion may vary from myelopathy, limitation of the neck movements or muscular weakness, atrophy and neurological sensory loss or associated with Klippel-Feil syndrome. ${ }^{14}$ It was reported that the fused vertebra not only structurally, but also functionally acts as one. ${ }^{15}$ Early detection and diagnosis helps to manage the symptoms through advising the patients to change the lifestyle. Earlier studies suggested increasing the awareness regarding the vertebral fusion. ${ }^{16}$ Interestingly, it was observed that there was no gender difference in the incidence of the fusion of the vertebra. ${ }^{17}$

\section{CONCLUSION}

The observed incidence of fused cervical vertebrae in the present study was $0.10 \%$. As the fusion of Cervical Vertebrae is associated with several clinical manifestations, early diagnosis is recommended. Further, more studies have to be undertaken in this area to understand and to diagnose early and also to develop more effective management techniques for the benefit of the society in general.

\section{REFERENCES}

[1] Wazir S, Mahajan A. Fusion of axis with third cervical vertebrae - a case report. Indian Journal of Fundamental and Applied Life Sciences 2011;1(4):164-6.

[2] Pate D. Normal radiographic differences between the adult and pediatric cervical spine. Dynamic Chiropractic 2012;30(4):284-8.

[3] Solan S. Fused axis vertebrae with a third cervical hemivertebrae - a rare case report. IOSR Journal of Dental and Medical Sciences 2013;10(4):83-5.

[4] Sonnesen L. Associations between the cervical vertebral column and craniofacial morphology. Article ID 295728, International Journal of Dentistry 2010;2010: p. 6.

[5] Tiwari A, Chandra N, Naresh M, et al. Congenital abnormal cervical vertebrae - a case report. J Anat Soc India 2002;51(1):68-9.

[6] Kulkarni V, Ramesh BR. A spectrum of vertebral synostosis. International Journal of Basic and Applied Medical Sciences 2012;2(2):71-7.

[7] Wazir S, Mahajan A. Fusion of axis with third cervical vertebra-a case report. Indian J Fundamental Appl Sci 2011;1(4):164-6.

[8] Meschan I. Analysis of roentgen signs in general radiology. Vol. 1. Philadelphia, London: WB Saunders Company 1973: p. 618-20.

[9] Brown MW, Templeton AW, Hodges FJ 3rd. The incidence of acquired and congenital fusions in the cervical spine. Am J Roentgenol Radium Ther Nucl Med 1964;92:1255-9.

[10] Samartzis DD, Herman J, Lubicky JP, et al. Classification of congenitally fused cervical patterns in Klippel-Feil patients: epidemiology and role in the development of cervical spine-related symptoms. Spine (Phila Pa 1976) 2006;31(21):E798-E804.

[11] Soni P, Sharma V, Sengupta J. Cervical vertebral anomalies-incidental findings on lateral cephalograms. The Angle Orthodontist 2008;78(1):176-80.

[12] Shands AR Jr, Bundensal WD. Congenital deformities of the spine. An analysis of the roentgenograms of 700 children. Bull Hosp Joint Disease 1956;17(2):110-33. 
[13] Sharma M, Baidwan S, Jindal AK, et al. A study of vertebral synostosis and its clinical significance. J Punjab Acad Forensic Med Toxicol 2013;13(1):20.

[14] Erdill H, Yildiz N, Cimen M. Congenital fusion of cervical vertebra \& its clinical significance. J Anat Soc India 2003;52(2):125-7.

[15] Dunsker SB, Brown 0, Thompson N. Craniovertebral anomalies. Clinical Neurosurgery 1980;27:430-9.
[16] Sherekar SK, Yadav YR, Basoor AS, et al. Clinical implication of alignment of upper \& lower cervical spine. Neurol India 2006;54(3):264-7.

[17] Usher BM, Christensen MN. A sequential developmental field defect of the vertebrae, ribs \& sternum, in a young woman of 12th century AD. American Journal of Physical Anthropology 2000;111(3):355-67. 